Revta brasil. Bot., São Paulo, V.23, n.3, p.225-230, set. 2000

\title{
Efeitos da deficiência de água em plantas de Euterpe oleracea (açaí)
}

\author{
MARIA ELISA RIBEIRO CALBO ${ }^{1,3}$ e JOSÉ ANTÔNIO P.V. DE MORAES ${ }^{2}$
}

(recebido em 1 de setembro de 1999; aceito em 10 de março de 2000)

\begin{abstract}
Effect of water deficit in Euterpe oleracea (açaí)). The water stress resistance of young açai plants Euterpe oleracea Mart. was determined in four-month-old plants, cultivated in punched black plastic bags filled with $7 \mathrm{~kg}$ of soil. The experiment was carried out in a greenhouse and irrigation was suspended until the photosynthesis drops to zero, after this moment daily irrigation was applied. During this dehydration period photosynthesis, stomatal conductance, and transpiration were measured daily. Small reductions in stomatal conductance, transpiration and photosynthesis were observed from the tenth day and became more pronounced with time. The photosynthetic rate fell to half of its maximum value when the water potential reached -1.9 MPa. After withholding irrigation for 61 days, the water stress was severe enough to reduce photosynthesis to zero; at this time the leaf water potential was - $2.5 \mathrm{MPa}$. Recovery of photosynthesis, stomatal conductance and transpiration started one day after rewatering and reached values similar to the control after two weeks of daily irrigation (rehydration). An osmotic potential reduction was calculated from leaf pressure-volume data, as a result the estimated osmotic adjustment was $0.29 \mathrm{MPa}$ at zero turgor and $0.36 \mathrm{MPa}$ at full turgor. Such osmotic adjustment indicates an açai adaptation mechanism to moderate water stress.
\end{abstract}

RESUMO - (Efeitos da deficiência de água em plantas de Euterpe oleracea (açaí)). A resistência de plantas jovens de açaí (Euterpe oleracea Mart.) à deficiência de água foi determinada em plantas de quatro meses de idade cultivadas em sacos plásticos perfurados contendo $7 \mathrm{~kg}$ de terra. $\mathrm{O}$ experimento foi conduzido em casa de vegetação e a irrigação foi suspensa até as plantas atingirem fotossíntese zero, quando, então, foram reidratadas. Durante este período foram feitas medidas diárias da fotossíntese líquida, condutância estomática e transpiração. Pequenas reduções na condutância estomática, transpiração e fotossíntese foram observadas a partir do décimo dia e se acentuaram com o tempo. A taxa de fotossíntese reduziu-se à metade da fotossíntese máxima quando o potencial de água atingiu -1,9 MPa. O estresse hídrico atingiu nível suficientemente severo para induzir uma fotossíntese nula após 61 dias sem irrigação, com um potencial de água médio foliar de -2,5 MPa. A recuperação da fotossíntese, condutância estomática e transpiração iniciaram-se um dia após a irrigação, atingindo valores semelhantes ao do controle após 14 dias de reidratação. A análise das curvas de pressão e volume mostrou que a deficiência de água diminuiu o potencial osmótico, resultando em um ajustamento osmótico de 0,29 MPa na turgescência zero e 0,36 MPa na turgescência máxima. Isto indica que essa espécie possui mecanismos de adaptação a um estresse hídrico moderado.

Key words - Euterpe oleracea, palms, photosynthesis, water stress

\section{Introdução}

O açaí, Euterpe oleracea Mart., é uma palmeira que ocorre nos estados do Pará, Amazonas, Maranhão e no Amapá, sendo freqüente em solos alagados e várzeas (Lorenzi et al. 1996). Pode atingir altura de até $25 \mathrm{~m}$, possui caule de 15 a $25 \mathrm{~cm}$ de diâmetro e ocorre geralmente formando touceiras com várias estipes. Sua madeira é utilizada em construções rústicas. Os frutos são do tipo baga de 1 a $1,5 \mathrm{~cm}$ de diâmetro de cor violácea, tornando-se quase negros depois de maduros, sendo utilizados para a confecção de licores, doces e sucos. As folhas são usadas para a cobertura de casas e na confecção

1. Departamento de Botânica, Universidade de Brasília, Caixa Postal 04457, 70919-970 Brasília, DF, Brasil.

2. Departamento de Botânica, Universidade Federal de São Carlos, Caixa Postal 676, 13565-905 São Carlos, SP, Brasil.

3. Autor para correspondência: mecalbo@unb.br de chapéus (Lorenzi 1992). A principal importância econômica desta espécie, no entanto, é como produtora de palmito, utilizado principalmente para a exportação. Estima-se que $95 \%$ de todo palmito produzido no Brasil seja extraído do açaizeiro (Nogueira 1995).

A água retida nos tecidos da planta é dependente do balanço entre a absorção de água do solo pelas raízes e a água perdida por transpiração. Disponibilidade de água no solo e outros fatores que reduzam a absorção e o transporte de água podem induzir uma deficiência hídrica nos tecidos. O principal fator que causa o estresse de falta de água nas plantas é a seca, que pode ser quase permanente em áreas desérticas, sazonal em áreas com estações definidas de chuva ou imprevisíveis como em climas muito úmidos (Kramer 1980).

Em condições naturais, mesmo plantas que possuem como habitat locais úmidos, como açaí, são submetidas a déficit de água em anos mais secos. A 
capacidade de tolerar um estresse moderado é importante para a propagação da espécie, em ambientes diferentes do seu habitat natural. A manutenção da integridade do aparelho fotossintético durante o estresse é significante como característica de resistência, uma vez que permite recuperação da fotossíntese após o estresse (Liu \& Dickmann 1993). O potencial de água no qual a fotossíntese torna-se nula depende das características adaptativas da espécie, do tempo de exposição, da severidade do déficit de água, do estádio de desenvolvimento da planta e da possibilidade de aclimatação ao estresse.

Muitas mesófitas podem se aclimatar a um estresse moderado de falta de água através de ajustamento osmótico, que possibilita a manutenção da turgescência celular e conseqüentemente o crescimento em potenciais de água foliares mais baixos. A manutenção da turgescência é obtida pela diminuição do potencial osmótico resultante do acúmulo de diferentes solutos no simplasma. $\mathrm{O}$ ajustamento osmótico tem sido utilizado como critério de seleção para tolerância ao estresse de falta de água entre espécies de eucalipto (Lemcoff et al. 1994), laranjeira (Medina et al. 1999) e genótipos de aveia (Frank et al. 1984).

O objetivo deste trabalho foi determinar a extensão dos efeitos da deficiência de água sobre a fotossíntese líquida, a condutância estomática e a transpiração e o tempo de recuperação da fotossíntese líquida após a irrigação de plantas de açaí que haviam atingido fotossíntese zero. Além disso, procurou-se detectar a existência de adaptação ao estresse de falta de água, através do ajustamento osmótico.

\section{Material e métodos}

As sementes de açaí, Euterpe oleracea Mart., foram coletadas em Belém, PA, tratadas com Captan 0,1\% e acondicionadas em sacos plásticos contendo serragem, acomodadas em caixas de papelão e enviadas para São Carlos, São Paulo. Para germinar, as sementes foram colocadas em bandejas e placas de Petri contendo vermiculita, em casa de vegetação e em estufa a temperatura de $25{ }^{\circ} \mathrm{C}$.

Após a emergência, as plântulas foram transplantadas para sacos plásticos pretos perfurados contendo $7 \mathrm{~kg}$ de solo adubado com NPK (10:10:10) e mantidas em casa de vegetação.

Aos quatro meses de idade a irrigação foi interrompida, submetendo as plantas ao estresse hídríco. Diariamente foram determinadas a taxa de fotossíntese, a condutância estomática e a transpiração em plantas sem irrigação e em plantas irrigadas com aproximadamente $250 \mathrm{~mL}$ de água por planta (controle).

As trocas gasosas foram avaliadas no modo diferencial com um analisador portátil de $\mathrm{CO}_{2}$ por infra vermelho (IRGA, Analytical Development Company (ADC) Hoddesdon, England, modelo LCA-2), acoplado a uma câmara foliar Parkinson do tipo PLC-2, alimentada por uma unidade de suprimento de ar ADC ASU (MF) e conectada a um processador e armazenador de dados DL-2. As medidas foram sempre efetuadas na primeira folha emitida de cada planta, no período da manhã, utilizando-se como fonte de luz uma lâmpada de projetor de slides a qual fornecia uma radiação fotossinteticamente ativa (RFA) em torno de $750 \mu \mathrm{mol} . \mathrm{m}^{-2} . \mathrm{s}^{-1}$ à superfície da câmara foliar. Este valor de RFA causou uma saturação lumínica para esta espécie, de acordo com a curva de intensidade de radiação versus fotossíntese, feita previamente (figura 1). Entre a fonte de luz e a câmara de exposição foi colocada uma cuba de vidro contendo uma lâmina de $14 \mathrm{~cm}$ de água, para reduzir o aquecimento da folha.

A folha mais velha de quatro plantas submetidas ao déficit de água e quatro das plantas irrigadas foram utilizadas para as determinações, sendo feitos pelo menos três registros de dados para cada folha. Quando a taxa de fotossíntese das plantas submetidas ao déficit de água atingiu o valor zero, as plantas voltaram a receber irrigação diária e as determinações de fotossíntese, condutância estomática e transpiração continuaram sendo feitas no período de recuperação até a fotossíntese alcançar valores similares ao controle.

Uma câmara de pressão modelo 1000 da PMS Instrument foi utilizada periodicamente para as determinações do potencial de água da folha e para a confecção de curvas de pressão e volume nas determinações do potencial osmótico.

Plantas irrigadas e as não irrigadas que atingiram fotossíntese zero foram utilizadas na confecção de curvas de pressão e volume (Tyree \& Hammel 1972, Cutler et al. 1979, Turner 1981). Com o ajuste da reta na parte linear da curva, estimou-se o potencial osmótico com a turgescência total (Cutler et al. 1979, Turner 1981). O ajustamento osmótico foi calculado pela diferença entre os valores de potencial osmótico com a turgescência total de plantas estressadas e os valores de potencial osmótico das plantas irrigadas. A turgescência $\Psi \mathrm{P}$ foi calculada pela diferença entre o potencial de água e o potencial osmótico.

\section{Resultados e Discussão}

Na equação utilizada para o ajuste da curva que relaciona taxa de fotossíntese e radiação fotossinteticamente ativa (RFA) (figura 1), obteve-se o valor $487 \mu$ mol. $\mathrm{m}^{-2} . \mathrm{s}^{-1}$ para a RFA que satura $90 \%$ da fotossíntese líquida e o ponto de compensação lumínico de $18,10 \mu \mathrm{mol} . \mathrm{m}^{-2} \cdot \mathrm{s}^{-1}$. Valores semelhantes de saturação lumínica foram obtidos para outras palmeiras como Elaeis guineensis (Corley 1983) e Mauritia vinifera (Calbo \& Moraes 1997).

Corley (1983) obteve valores médios de fotossíntese com luz saturante em torno de $10 \mu \mathrm{mol} \cdot \mathrm{m}^{-2} \cdot \mathrm{s}^{-1}$ em folhas de Elaeis guineensis com 10 anos de idade. 


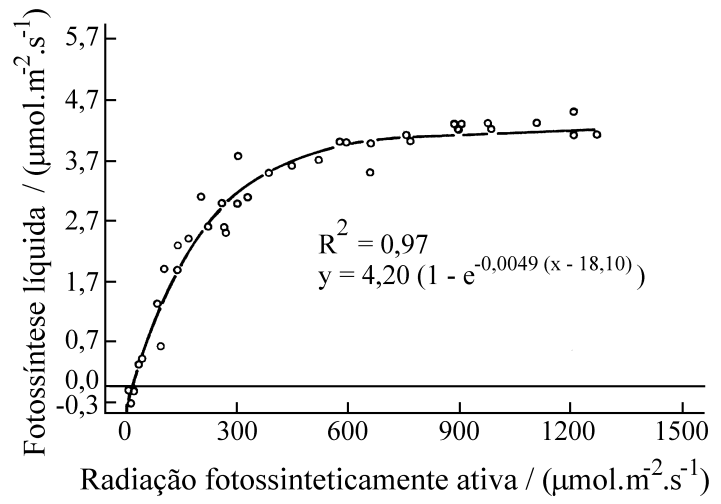

Figura 1. Fotossíntese líquida $\left(\mu \mathrm{mol} \cdot \mathrm{m}^{-2} \cdot \mathrm{s}^{-1}\right)$ em função da radiação fotossinteticamente ativa (RFA) em folhas de plantas jovens de açaí.

Nas espécies de palmeiras de deserto Erythea armata e Washingtonia filifera a fotossíntese líquida foi 4,37 e $8,02 \mu \mathrm{mol} . \mathrm{m}^{-2} . \mathrm{s}^{-1}$, respectivamente, com uma radiação fotossinteticamente ativa em torno de $2000 \mu \mathrm{mol} . \mathrm{m}^{-2}$. $\mathrm{s}^{-1}$ (Schmitt et al. 1993). Larcher (1995) cita que a capacidade fotossintética de palmeiras varia em geral de 4 a 10, no entanto, algumas espécies podem atingir valores de até $20 \mu \mathrm{mol} . \mathrm{m}^{-2} \cdot \mathrm{s}^{-1}$.

A fotossíntese líquida de plantas submetidas à falta de água reduziu-se a zero 61 dias após a suspensão da irrigação (figura 2A). Pequenas reduções na fotossíntese, condutância estomática e transpiração foram observadas a partir do décimo dia e se acentuaram com o tempo (figura 2).

A taxa de fotossíntese reduziu-se à metade dos valores de fotossíntese máxima após 35 dias sem irrigação e atingiu zero aos 61 dias sob um potencial de água em torno de -2,5 MPa (tabela 1). Dados semelhantes foram obtidos em folhas de soja (Turner 1979), onde o potencial de água com fotossíntese zero foi -2,5 MPa e em alguns cultivares de girassol, onde encontrou-se aproximadamente -2,1 MPa (Mojayad \& Planchon 1994). Em plantas de buriti, o valor do potencial de água com fotossíntese zero foi de -2,1 MPa (Calbo \& Moraes 1997). Se for considerado que plantas mesófitas atingem fotossíntese zero com potenciais de água até -2,5 MPa (Larcher 1995), os resultados com açaí indicam características de plantas mesófitas quanto à tolerância à seca moderada.
O fechamento estomático ocorreu no $53^{\circ}$ dia, quando o potencial da água era $-2,4 \mathrm{MPa}$ (tabela 1 ), apresentando pequenas oscilações até o $61^{\circ}$ dia (figura 2B). A taxa de transpiração diminuiu gradativamente com o tempo, acompanhando a redução da condutância estomática (figura 2C).

As plantas normalmente apresentam um decréscimo paralelo entre a fotossíntese e a condutância estomática à medida que o déficit de água se torna mais severo (Ni \& Pallardy 1992). A abertura estomática regula a saída de vapor de água da planta e, ao mesmo tempo, a entrada de $\mathrm{CO}_{2}$ para a fotossíntese. Geralmente a taxa de fotossíntese decresce a níveis próximos de zero em potencias de água que induzem o fechamento estomático (Turner 1979).

A recuperação da taxa de fotossíntese nas plantas não irrigadas por 61 dias iniciou-se no dia seguinte à irrigação, porém só atingiu valores similares ao controle após 14 dias de reidratação (figura 3A). Do primeiro ao quarto dia houve uma recuperação da taxa de fotossíntese líquida em torno de $37 \%$, do quinto ao oitavo dia a recuperação foi de $40 \%$ e no nono dia já era de $62 \%$, permanecendo este valor mais ou menos constante até o $11^{\circ}$ dia. A partir do $12^{\circ}$ dia, houve maior recuperação diária da taxa de fotossíntese até $14^{\circ}$ dia, quando esta foi totalmente recuperada.

A condutância estomática (figura 3B) recuperou-se em aproximadamente $23 \%$ no oitavo dia, já no nono dia era de $56 \%$ e no $12^{\circ}$ dia $90 \%$, atingindo os valores do controle no $14^{\circ}$ dia. A taxa de transpiração também aumentou gradativamente após a irrigação e no $14^{\circ}$ dia atingiu o valor das plantas irrigadas (figura 3C).

A lenta recuperação da condutância estomática após um período de estresse de água é atribuída por alguns autores à alta concentração de ácido abscísico (ABA) acumulado durante o estresse hídrico (Mansfield \& Davies 1985). A condutância estomática é

Tabela 1. Potencial de água (MPa) em plantas de açaí, submetidas a diferentes períodos sem irrigação.

\begin{tabular}{ll}
\hline Dias sem irrigação & $\psi \alpha$ \\
\hline 1 & $-0,2$ \\
35 & $-1,9$ \\
53 & $-2,4$ \\
61 & $-2,5$ \\
\hline
\end{tabular}



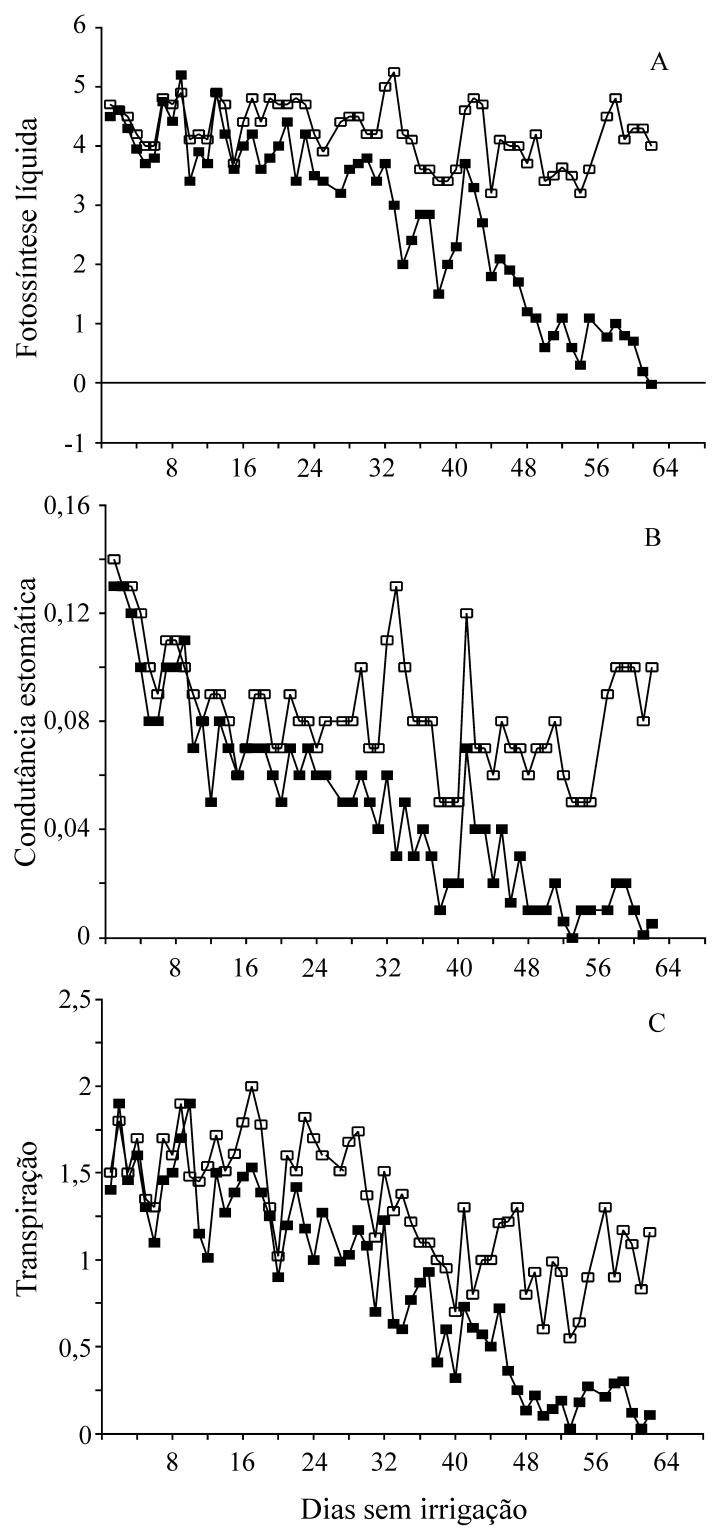

Figura 2. Fotossíntese líquida $\left(\mu \mathrm{mol} \cdot \mathrm{m}^{-2} \cdot \mathrm{s}^{-1}\right)(\mathrm{A})$, condutância estomática $\left(\mathrm{mol} \cdot \mathrm{m}^{-2} \cdot \mathrm{s}^{-1}\right)(\mathrm{B})$ e transpiração $\left(\mathrm{mmol} \cdot \mathrm{m}^{-2} \cdot \mathrm{s}^{-1}\right)(\mathrm{C})$, em plantas de açaí durante o estresse hídrico induzido. ( $\square$ sem irrigação $(\square)$ controle.

recuperada apenas quando a concentração de $\mathrm{ABA}$ diminui e o tempo gasto para esta recuperação varia com o grau de estresse a que a planta foi submetida e com a espécie (Bengton et al. 1977). Ludlow et al. (1980) observaram, em Panicum maximum, que a taxa de recuperação da fotossíntese após a reidratação das plantas foi inversamente relacionada com o estresse experimentado; plantas que apresentaram um potencial de água mais baixo e foram reidratadas demoraram mais tempo para recuperar a fotossíntese. A lenta indução do estresse em plantas de açaí e o potencial de água baixo atingido antes da reidratação pode ter possibilitado uma produção maior de ABA nestas plantas. Este acúmulo de ABA permite que a planta conserve o turgor através da manutenção de baixa condutância estomática (Mansfield \& Davies 1985). Diferenças genéticas entre espécies na produção de $\mathrm{ABA}$ também têm sido relatadas (Chaves 1991).

Uma rápida recuperação da fotossíntese líquida após um estresse hídrico parece ser característica de plantas mais resistentes ao estresse de água (Ludlow et al. 1980). O tempo gasto na recuperação da fotossíntese em plantas de açaí foi relativamente grande e esta lenta recuperação pode indicar um efeito mais intenso do estresse hídrico no aparelho fotossintético e talvez um maior armazenamento de $\mathrm{ABA}$, o qual não foi quantificado.

Os valores de potenciais osmóticos apresentados na tabela 2 indicam que o estresse de água induziu um decréscimo no potencial osmótico de $20,2 \%$ com a turgescência total e $14,21 \%$ com a turgescência zero. Decréscimos no potencial osmótico, atribuídos a um ajustamento osmótico após estresse hídrico, já foram encontrados em várias espécies como sorgo (Jones 1978), videira (Rodrigues et al. 1993), aveia (Morgan 1984), eucalipto (Lemcoff et al. 1994) e buriti (Calbo \& Moraes 1997).

Os potenciais osmóticos com turgescência total obtidos para plantas jovens de açaí irrigadas $(-1,42$ $\pm 0,02)$ e após o estresse hídrico $(-1,78 \mathrm{MPa} \pm 0,03)$ (tabela 2), estão na faixa de valores encontrados para a maioria das espécies cultivadas, as quais, segundo

Tabela 2. Potencial osmótico (MPa) com turgescência total $\left(\Psi \pi^{100}\right)$ e com turgescência zero $\left(\Psi \pi^{0}\right)$ em plantas de açaí submetidas ao déficit de água durante 61 dias e em plantas irrigadas. (Média \pm erro padrão).

\begin{tabular}{lcc}
\hline & $\Psi \pi^{100}$ & $\Psi \pi^{0}$ \\
\hline Irrigadas & $-1,42 \pm 0,02$ & $-1,75 \pm 0,03$ \\
Estresse hídrico & $-1,78 \pm 0,03$ & $-2,04 \pm 0,06$ \\
\hline
\end{tabular}



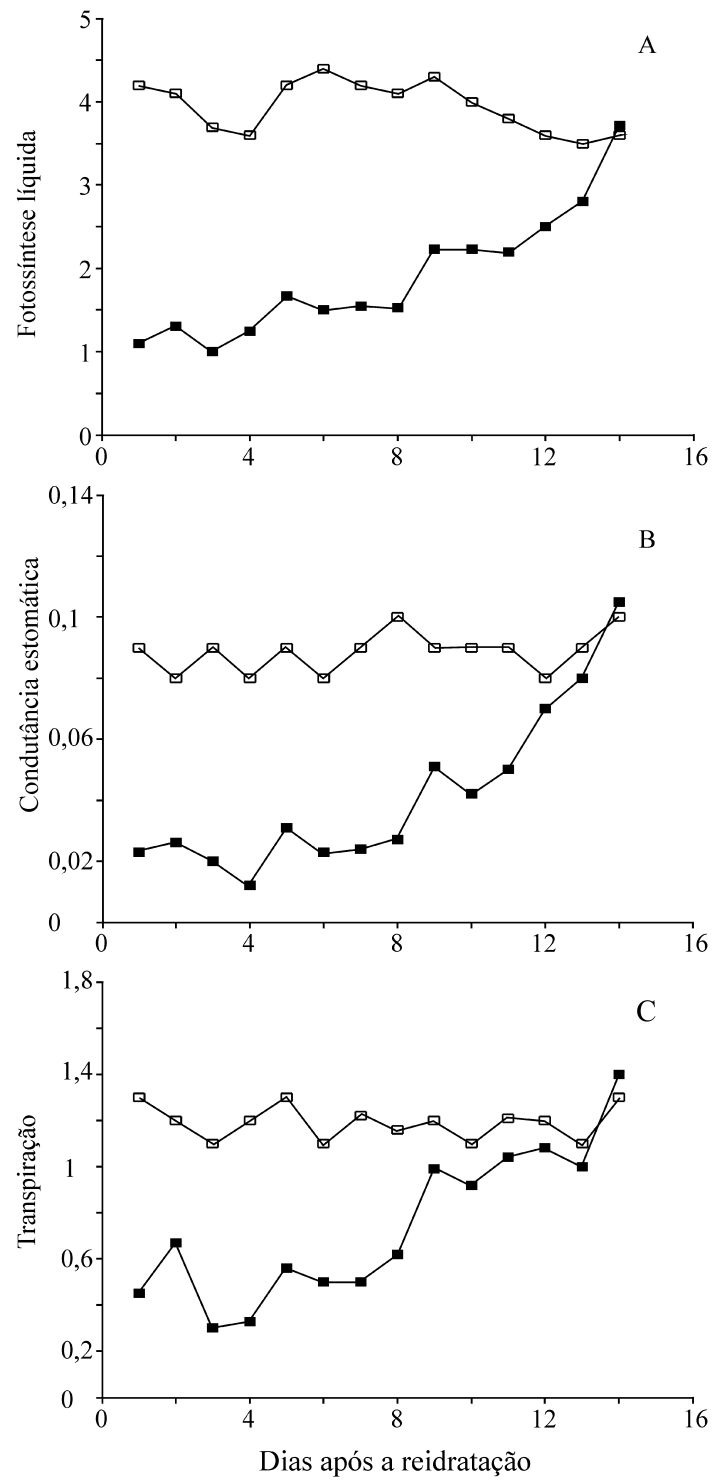

Figura 3. Fotossíntese líquida $\left(\mu \mathrm{mol} \cdot \mathrm{m}^{-2} \cdot \mathrm{s}^{-1}\right)(\mathrm{A})$, condutância estomática $\left(\right.$ mol.m $\left.\mathrm{m}^{-2} \cdot \mathrm{s}^{-1}\right)(\mathrm{B})$ e transpiração $\left(\mathrm{mmol} \cdot \mathrm{m}^{-2} \cdot \mathrm{s}^{-1}\right)(\mathrm{C})$, de plantas de açaí irrigadas após 61 dias sem irrigação. reidratadas $(\square)$ controle.

Larcher (1995) atingem valores de potencial osmótico de até - 2,1 MPa. A diferença entre o potencial osmótico de plantas irrigadas e plantas estressadas com turgescência total foi de - 0,36 MPa. Estes valores estão na faixa de valores típicos de decréscimo no potencial osmótico de espécies mesó- fitas, os quais têm sido relatados como sendo de - 0,2 a $-0,6 \mathrm{MPa}$ para arroz, 0 a $-1,0 \mathrm{MPa}$ para aveia, $-0,3 \mathrm{MPa}$ para sorgo e milho e -0,2 MPa para folhas de laranjeira (Morgan 1984).

O decréscimo no potencial osmótico indica que o açaí possui mecanismos para tolerar um estresse moderado de falta de água, típico de espécies mesófitas.

Agradecimentos - Os autores agradecem ao Dr. Cláudio Reis de Carvalho (Pesquisador do Centro de Pesquisa Agro-Pecuário do Trópico Úmido) pelo fornecimento das sementes de açaí.

\section{Referências bibliográficas}

BENGTON, C., FALK, S. \& LARSSON, S. 1977. The after-effect of water stress on transpiration rate and change in abscisic acid content of young wheat plants. Physiologia Plantarum 41:149-154.

CALBO, M.E.R. \& MORAES, J.A.P.V. 1997. Fotossíntese, condutância estomática, transpiração e ajustamento osmótico de plantas de buriti submetidas a estresse hídrico. Revista Brasileira de Fisiologia Vegetal 9:117-123.

CHAVES, M.M. 1991. Effects of water deficits on carbon assimilation. Journal of Experimental Botany 42:1-6.

CORLEY, R.H.V. 1983. Photosynthesis and age of oil palm leaves. Photosynthetica 17:97-100.

CUTLER, J.M., SHAHAN, K.W. \& STEPONKUS, P.L. 1979. Characterization of internal water relations of rice by a pressure-volume method. Crop Science 19:681-685.

FRANK, A.B., BARKER, R.E. \& BERDAHL, J.D. 1984. Pressure-volume characteristics of genotypes of three wheatgrass species. Crop Science 24:217-220.

JONES, M.M. 1978. Osmotic adjustment in leaves of sorghum in response to water deficits. Plant Physiology 61:122-126.

KRAMER, P.J. 1980. Drought, stress, and the origin of adaptations. In Adaptation of plants to water and high temperature stress. (N.C. Turner, J.P. Kramer, eds.). Wiley, New York, p.7-20.

LARCHER, W. 1995. Physiological Plant Ecology. Springer-Verlag, New York.

LEMCOFF, J.L., GUARNASCHELL, A.B., GARAU, A.M., BASCIALLI, M.E. \& GHERSA, C.M. 1994. Osmotic adjustment and its use as a selection criterion in Eucalyptus seedlings. Canadian Journal Forest Research 24:2404-2408.

LIU, C.H. \& DICKMANN, D.I. 1993. Responses of two hybrid clones to flooding, drought, and nitrogen availability. II. Gas exchange and water relations. Canadian Journal of Botany 71:927-938.

LORENZI, H. 1992. Árvores brasileiras: manual de identificação e cultivo de plantas arbóreas nativas do Brasil. Editora Plantarum, Nova Odessa.

LORENZI, H., SOUZA, H.M., COSTA, J.T.M., CERQUEIRA, L.S.C. \& BEHR, N. 1996. Palmeiras do Brasil: nativas e exóticas. Editora Plantarum. Nova Odessa. 
LUDLOW, M.M., NG, T.T. \& FORD, C.W. 1980. Recovery after water stress of leaf gas exchange in Panicum maximum var. trichoglume. Australian Journal of Plant Physiology 7:299313 .

MANSFIELD, T.A. \& DAVIES, W.J. 1985. Mechanisms for leaf control of gas exchange. BioScience 35:158-164.

MEDINA, C.L., MACHADO, E.C. \& GOMES, M.M.A. 1999. Condutância estomática, transpiração e fotossíntese em laranjeira "Valência" sob deficiência hídrica. Revista Brasileira de Fisiologia Vegetal 11:29-34.

MOJAYAD, F. \& PLANCHON, C. 1994. Stomatal and photosynthetic adjustment to water deficit as the expression of heterosis in sunflower. Crop Science 34:103-107.

MORGAN, J.M. 1984. Osmoregulation and water stress in higher plants. Annual Review of Plant Physiology 35:289-319.

NI, B. \& PALLARDY, S.G. 1992. Stomatal and non stomatal limitation to net photosynthesis in seedlings of woody angiosperms. Plant Physiology 99:1502-1508.

NOGUEIRA, O.L. 1995. A cultura do açaí. EMBRAPA-SPI, Brasília.
RODRIGUES, M.L., CHAVES, M.M., WENDLER, R., DAVID, M.M., QUICK, W.P., LEEGOOD, R.C., STITT, M. \& PEREIRA, J.S. 1993. Osmotic adjustment in water stressed grapevine leaves in relation to carbon assimilation. Australian Journal Plant Physiology 20:309-321.

SCHMITT, A.K., MARTIN, C.E., LOESCHEN, S.L. \& SCHMITT, A. 1993. Mid-summer gas exchange and water relations of seven $\mathrm{C}_{3}$ species in a desert wash in baja California, Mexico. Journal Arid Environments 24:155-164.

TURNER, N.C. 1979. Drought resistance and adaptation to water deficits in crop plants. In Stress physiology in crop plants. (H. Mussel, R.C. Staples, eds.) Wiley Interscience, New York, p.468-478.

TURNER, N.C. 1981. Techniques and experimental approaches for the measurement of plant water status. Plant Soil 58:339-366.

TYREE, M.T. \& HAMMEL, H.T. 1972. The measurement of the turgor pressure and the water relations of plants by the pressure- bomb technique. Journal of Experimental Botany $23: 276-282$ 